\title{
Are Imidazoles Versatile or Promiscuous in Reactions with Organophosphates? Insights from the Case of Parathion
}

\author{
Valmir B. Silva ${ }^{a}$ and Elisa S. Orth ${ }^{\circledR * a}$ \\ ${ }^{a}$ Departamento de Química, Universidade Federal do Paraná (UFPR), \\ CP 19081, 81531-990 Curitiba-PR, Brazil
}

\begin{abstract}
Is the broad mechanistic versatility of imidazole towards organophosphates (OPs), that has inspired many catalysts and sensors, beneficial? Herein, a thorough analysis is given seeking to unravel this puzzle. For OPs from the $\mathrm{P}=\mathrm{O}$ family, imidazole attacks the phosphorus atom exclusively ( $N$-phosphorylates). With the $\mathrm{P}=\mathrm{S}$ family which are less reactive, an unusual $\mathrm{N}$-alkylation predominates. Surprisingly, imidazole reacts with methyl parathion exclusively at the aliphatic carbon, whilst for the ethylated analogue parathion, imidazole reacts by two pathways: at both the phosphorus and aliphatic carbon, with predominance for the latter. The preference for the electrophilic center can be modulated by the $\mathrm{pH}$. Overall, a mechanistic structure-related trend is observed: imidazole tends to prefer other electrophilic centers than the phosphorus for less reactive OPs. Moreover, this gives important insights concerning the challenging chemistry of imidazole alkylation and the outcomes for monitoring systems that depend on the detection of degradation products. Finally, a thorough comparison with the literature is presented seeking to understand how imidazole reacts towards various OPs. We suggest that the promiscuity of imidazole boosts up its versatility.
\end{abstract}

Keywords: methyl parathion, organothiophosphate, organophosphorus, $N$-alkylation

\section{Introduction}

Efficient cleavage of $\mathrm{P}-\mathrm{O}$ bonds in organophosphates and organothiophosphates (OPs) remains a challenge in chemical security. These compounds can be very toxic and are extensively used in flame retardants, chemical weapons and agrochemicals. The irregular use, environmental contamination, human intoxication and imminent threat with chemical attacks are a current worldwide concern related to the chemistry of OPs. ${ }^{1-3}$ Indeed, the extensive use of agrochemicals has raised the radar towards the development of reliable monitoring systems and destruction processes for unused stockpiles. Intrinsically related to this is the issue of chemical war. Albeit the use of chemical warfare seemed to be used only during world wars, they continue to be a prevailing risk since they have been used in terrorist attacks such as at the subway in Tokyo (1995), in the recent Syrian war and even in assassination attempts (Russian spy in 2018 in UK). ${ }^{4}$ Hence, the overall development of efficient decontamination / monitoring systems is crucial to protect modern society. All these efforts rely primarily on the concise understanding of

*e-mail: elisaorth@ufpr.br the reaction mechanisms involved, since they dictate the favorable pathways and indicate the less-toxic products. For example, one of the possible degradation products upon hydrolysis of the nerve agent VX is $S$-2-(diisopropylaminoethyl) methylphosphonothioic acid, which has almost the same toxicity compared to VX. Thus, this reaction pathway would not be desirable when neutralizing a warhead of this agent and scientists need to strategically design a secure reaction that leads to less-toxic products. ${ }^{5}$ Curiously, despite the relatively simple chemical structure of OPs, there is no unanimous understanding on how the reactions proceed and subtle structural changes can drastically shift the mechanistic course. For example, the phosphoryl $(\mathrm{P}=\mathrm{O})$ or analogous thiophosphoryl $(\mathrm{P}=\mathrm{S})$ can present different electrophilic centers or even the aliphatic / aromatic groups anchored to the phosphoryl moiety can tune the mechanism. ${ }^{6}$

Besides the synthetic applications (and threats) of the OPs, they are the pillars of deoxyribonucleic acid (DNA), ribonucleic acid (RNA) and other biological molecules. In the biological systems, the phosphoryl transfers are always mediated by enzymatic process. Thus, bioinspired systems are interesting approach to develop prominent phosphoryl transfer catalysts and understand their paths. In this sense, the 
presence of the aminoacid histidine containing the imidazole group in several active sites of enzymes such as proteases and ribonucleases (RNases) is an interesting indicative of its importance in biological catalysis. Histidine was discovered before 1900's by Hedel and Kossel independently, and gained attention due to their biological properties. ${ }^{7}$ Inspired by this amino acid, Pyman deepened the chemistry of imidazole (former called glyoxalines) during more than 20 years until his death in $1944 .^{8}$ Several studies were published involving the isolation of imidazole derivatives, properties and synthesis of several small imidazole derivatives with different substituents and positions, opening the possibilities with this class. The great catalytic versatility of imidazoles is mainly due to their $\mathrm{p} K_{\mathrm{a}}$ near 7 , guaranteeing to act efficiently as an acid, base or nucleophilic catalyst. Due to the catalytic properties of imidazole and its derivatives, they were extensively studied as catalysts in acyl transfer reactions since the 50's as well as the implications in enzymatic catalysis. $^{9-11}$ During several decades, understanding the reactivity of imidazole and its derivatives has been a matter of interest. Simultaneously, phosphoryl transfer mediated by imidazole started to be evaluated. Mainly in the 90's, several studies were published discussing the central role of imidazole in enzymatic phosphorylation. ${ }^{12-14}$

The promising imidazoles have been increasingly employed in several reactions with synthetic and hazardous OPs for detoxifying processes or sensors. In this sense, mechanistic studies are benchmarks towards optima methods. Ba-Saif and Williams ${ }^{15}$ studied phosphate triesters in reactions with imidazole, varying the leaving group and concluded that imidazole is an efficient catalyst for phosphoryl transfer and collected good indications in favor of a concerted mechanism at the phosphorus atom. Recently the "thio effect" (i.e., the effect caused by exchanging the $\mathrm{P}=\mathrm{O}$ by a $\mathrm{P}=\mathrm{S}$ bond in OPs) became a matter of interest in reactions with organophosphates, where the solvent effect and the nature of nucleophiles were evaluated. ${ }^{16,17}$ In this sense, Aguayo et al. ${ }^{6}$ studied the reaction of several pyridine and phenol derivatives with diethyl 2,4-dinitrophenylphosphate (DEDNPP) and diethyl 2,4-dinitrophenylthiophosphate (DEDNPSP). The results showed nucleophilic attacks at the aromatic carbon and phosphorus in different proportions, for pyridine nucleophiles. Moreover, the attack at phosphorus was always majority for DEDNPP in contrast to DEDNPSP. ${ }^{6}$ Rougier et al. ${ }^{18}$ studied the reaction of fenitrothion (thiophosphate structurally related to parathion) with some $\alpha$-nucleophiles and observed that nitrogenated nucleophiles attack the phosphorus and aliphatic carbons. Indeed, there is no straightforward mechanistic trend of OPs containing $\mathrm{P}=\mathrm{O}$ or its analogue with $\mathrm{P}=\mathrm{S}$ and this comprehensive understanding related to structure is essential since this is one of the most valuable tools for destroying these compounds, leading to knowingly less toxic substances. Further, this inherent mechanistic puzzle of OPs can be potentiated when considering reactions with nucleophiles, since their structure can also define the reactivity and most favorable pathways. Our research group has been studying some reactions with imidazole and the OPs compounds DEDNPP, ${ }^{19}$ paraoxon, ${ }^{20}$ and methyl parathion, shown in Figure $1 .^{21}$ Interestingly, with the $\mathrm{P}=\mathrm{O}$ containing phosphates (DEDNPP and paraoxon), the imidazole attacks only the phosphorus center leading to an unstable imidazole phosphoryl intermediate and subsequently to diethyl phosphate and the nitrophenolate product. In this case, imidazole acts as an authentic catalyst generating less toxic products. On the other hand, with the thiophosphate $(\mathrm{P}=\mathrm{S})$ methyl parathion, imidazole unexpectedly attacks solely the aliphatic carbon (Figure 1) leading to 1-methylimidazole and methyl 4-nitrophenylthiophosphoric acid. The imidazole alkylation with methyl parathion is unusual under such mild conditions (aqueous, weakly basic). It brings unprecedented advances towards the synthesis of alkylated imidazoles and also sheds light to the comprehensive understanding on the action of imidazole towards OPs with varying structures. Besides the high rates enhancement in relation to the spontaneous hydrolysis ( $>10^{5}$ fold) for these reactions, imidazole showed attack exclusively at one electrophilic center (phosphorus or aliphatic carbon) depending on the OPs structure. Imidazole, other than versatile can also be promiscuous? This opens some questions about the driving force in reactions of imidazole with OPs. What is the role of the aliphatic group and of $\mathrm{P}=\mathrm{O}$ vs. $\mathrm{P}=\mathrm{S}$ in the reactivity? Is imidazole a good candidate towards chemical detoxification and can some structure related trends be predicted?

As discussed above for OPs, their reactivity is strongly affected by their structure and the nature of the nucleophile. Imidazole presented a completely different behavior in reactions with paraoxon and methyl parathion, although they are very similar. Hence, a detoxifying agent could be promising to destroy one pesticide and poor to destroy another. Understanding reactivity permits to develop ideal reaction systems. Herein, we wanted to evaluate the structural effect of parathion (Figure 1), an analogue of methyl parathion, which contains ethyl groups instead of methyl. We carried out a kinetic and mechanistic study for the reaction of parathion with imidazole in aqueous medium. The influence in the reactivity of the aliphatic moiety in parathion and its analogues is still poorly explored in the literature. We seek a broader understanding on the (i) thio effect, (ii) substituent effect related to aliphatic moiety of OPs and (iii) evaluate the mechanistic versatility of the potent imidazole. 


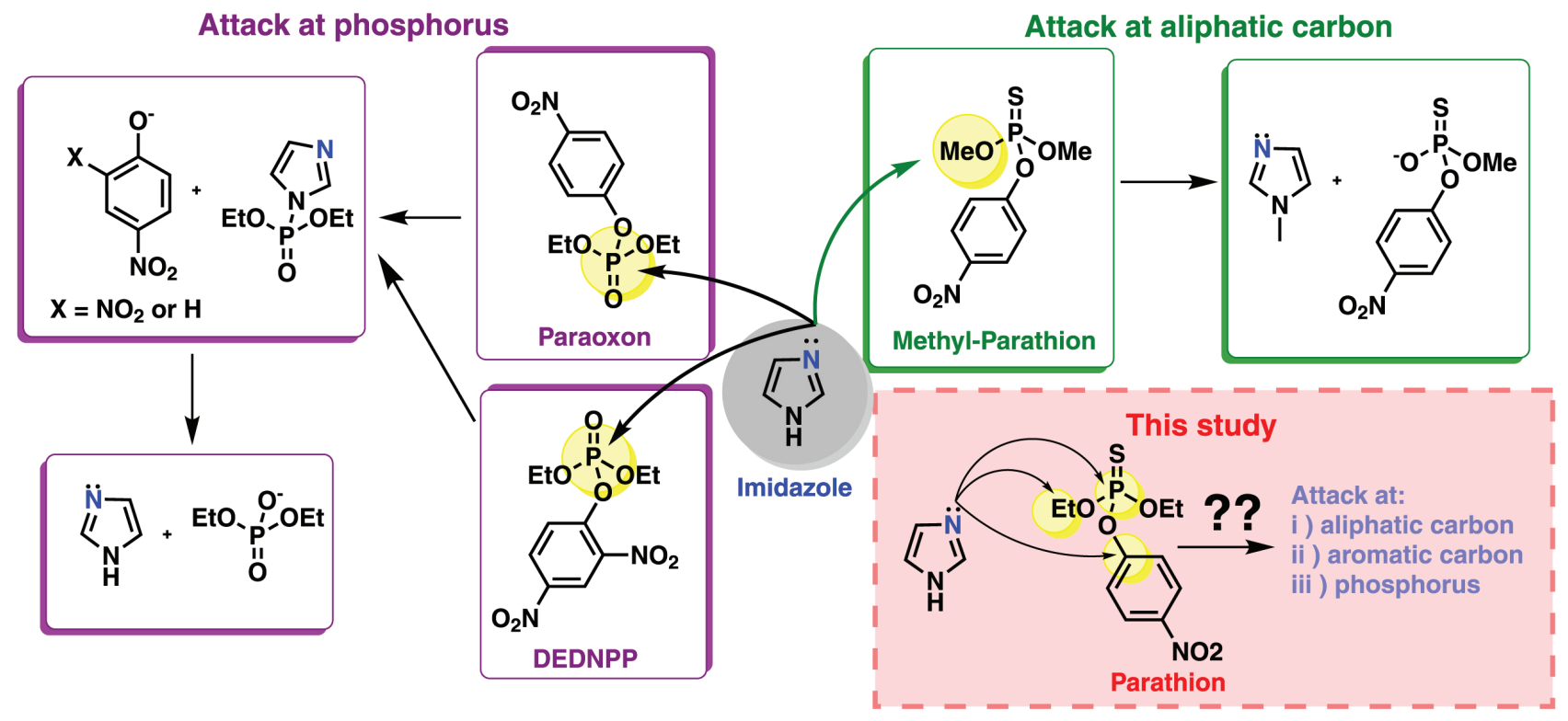

Figure 1. Summary of some reactions of imidazole with several OPs and the overall question raised in the present study.

\section{Experimental}

The reagents 4-nitrophenol (Sigma-Aldrich), carbon tetrachloride (Merck), elemental sulfur (Ecibra), pyridine (Merck), acetonitrile (Carlo-Erba), imidazole (SigmaAldrich), deuterium oxide (Sigma-Aldrich), sodium hydroxide (Sigma-Aldrich) and hydrochloric acid (Panreac) were used without further purification. The reagents ethanol (Álcool da Ilha), phosphorus trichloride (Sigma-Aldrich), $n$-hexane (Dipa Química) and ethyl acetate (Bandeirante Brazmo) were purified by distillation before use.

\section{Synthesis of parathion}

Parathion was synthesized according to the literature ${ }^{22}$ and modified as follows. In a flask equipped with reflux condenser and under $\mathrm{N}_{2}$ atmosphere, $1.53 \mathrm{~g}(11 \mathrm{mmol})$ of 4-nitrophenol solubilized in carbon tetrachloride was added dropwise to $0.88 \mathrm{~mL}$ ( $10 \mathrm{mmol})$ of phosphorus trichloride. During the addition, the color of the reaction media became violet. The reaction was maintained at $60{ }^{\circ} \mathrm{C}$ during $30 \mathrm{~min}$. The reaction flask was allowed to cool to room temperature and $340 \mathrm{mg}(10 \mathrm{mmol})$ of elemental sulfur was added. The reaction was maintained at reflux conditions overnight. The reaction flask was allowed to cool to room temperature and the unreacted sulfur was removed by filtration. A mixture of dry ethanol $(10 \mathrm{mmol})$ and pyridine $(10 \mathrm{mmol})$ was added dropwise to the filtrate. The reaction was maintained at $60{ }^{\circ} \mathrm{C}$ during $30 \mathrm{~min}$, allowed to cool to room temperature and extracted with water ( 3 times $25 \mathrm{~mL}$ ). The aqueous phase was discarded. The organic phase was concentrated under reduced pressure and the crude product was purified by flash chromatography (hexane/ethyl acetate, 9:1, v/v). It was obtained $580 \mathrm{mg}$ ( $2 \mathrm{mmol}$ ) of parathion ( $20 \%$ yield) as a yellow viscous liquid. ${ }^{1} \mathrm{H}$ and ${ }^{31} \mathrm{P}$ NMR spectra are presented in the Supplementary Information (SI) section, Figures S1 and $\mathrm{S} 2$, and agree with the literature. ${ }^{23}{ }^{1} \mathrm{H}$ nuclear magnetic resonance (NMR) $\left(200 \mathrm{MHz}, \mathrm{CDCl}_{3}\right.$, tetramethylsilane (TMS)) $\delta 1.39\left(\mathrm{td}, J_{\mathrm{HH}} 7.09, J_{\mathrm{HP}} 0.96 \mathrm{~Hz}, 6 \mathrm{H}\right), 4.27(\mathrm{dq}$, $\left.J_{\mathrm{HP}} 9.99, J_{\mathrm{HH}} 7.09 \mathrm{~Hz}, 4 \mathrm{H}\right), 7.34$ and 8.35 (AA'BB', aromatic, $4 \mathrm{H}) ;{ }^{31} \mathrm{P}$ NMR $\left(80 \mathrm{MHz}, \mathrm{CDCl}_{3}, \mathrm{H}_{3} \mathrm{PO}_{4}\right) \delta 61.9$ (quintet, $\left.J_{\mathrm{PH}} 9.9 \mathrm{~Hz}\right)$.

\section{Kinetic measurements}

The reactions were followed by UV-Vis spectroscopy (Agilent Cary 60) monitoring the absorbance between 200-700 $\mathrm{nm}$. The reactions started with the addition of an aliquot $(30 \mu \mathrm{L})$ of a stock solution of parathion $\left(6.8 \times 10^{-3} \mathrm{~mol} \mathrm{~L}^{-1}\right.$ in acetonitrile) in $3 \mathrm{~mL}$ of a buffered solution (pH 6-9) of imidazole ( $0.75 \mathrm{~mol} \mathrm{~L}^{-1}$ in Milli-Q water) in a quartz cuvette with $1 \mathrm{~cm}$ optical path under $70{ }^{\circ} \mathrm{C}$ controlled by an ultrathermostatic bath (SP Labor SP-152). The kinetic profiles of absorbance $v s$. time were fitted according to pseudo-first order equations using iterative least-squares software. ${ }^{21}$

\section{NMR analysis}

The reactions were performed directly in the NMR tube mixing an aliquot of imidazole $0.3 \mathrm{~mol} \mathrm{~L}^{-1}(300 \mu \mathrm{L})$ in $\mathrm{D}_{2} \mathrm{O}\left(\mathrm{pD} 7.2\right.$ and 8.2), parathion $0.15 \mathrm{~mol} \mathrm{~L}^{-1}$ in acetonitrile 
$(30 \mu \mathrm{L})$ and acetonitrile- $d_{3}(200 \mu \mathrm{L})$. The reaction media was maintained at $80^{\circ} \mathrm{C}$ using a thermostatic bath (Haake $\mathrm{C} 10)$. The equipment used was an NMR Bruker DPX 200 operating with $4.7 \mathrm{~T}, 200 \mathrm{MHz}$ for ${ }^{1} \mathrm{H}$ and $80 \mathrm{MHz}$ for ${ }^{31} \mathrm{P}$, with 3-(trimethylsilyl) propionic-2,2,3,3- $d_{4}$ acid sodium salt (TMSP), and $\mathrm{H}_{3} \mathrm{PO}_{4}$ capillary as reference, respectively.

\section{Results and Discussion}

The reaction of imidazole with parathion can undergo three possible pathways, as depicted in Figure 2. Imidazole can attack the phosphorus atom, leading to 4-nitrophenol (PNP) and a phosphorylated intermediate (IMZP), which can hydrolyse easily, resulting in the phosphoric acid derivative, DNEPT (path A, Figure 2). This pathway has been confirmed in many previous studies with $\mathrm{OPs}$ of the $\mathrm{P}=\mathrm{O}$ family, evidenced by the detection of the phosphorylated intermediates, showing reasonable lifetimes..$^{19,20,24}$ Another possible pathway for the reaction of imidazole with parathion is at the aliphatic carbon, leading to the products: diester ethyl 4-nitrophenylthiophosphoric acid (DEPT) and ethylated imidazole 1-ETI, (path B, Figure 2). This odd attack that forms alkylated imidazole under such mild conditions (aqueous, weakly basic) is peculiar and had been evidenced for the first time to occur exclusively by this means in the reaction of imidazole with methyl parathion, in a previous study. ${ }^{21}$ Aside from the extraordinary impact that the facile alkylation of imidazole can bring to the field of organic synthesis, this pathway has important consequences when targeting chemical detoxification of OPs, since products of different nature are produced. Methyl parathion is very similar to parathion (contains ethyl groups instead of methyl), so one would expect that the same mechanism drives the reaction. Whereas, we will show that this is not a general rule and that even subtle structural changes can shift the mechanistic outcome. Finally, the last pathway that can occur herein is the attack of imidazole at the aromatic carbon of parathion, giving DNEPT and the derivative 1-NIMZ (path C, Figure 2). This path should be the least favorable one with imidazole (no reports to date) ${ }^{19,21}$ and occurs predominantly with alpha-nucleophiles. ${ }^{25}$ In order to infer how the reactions occur, a thorough kinetic study was carried out as well as it was followed by ${ }^{1} \mathrm{H}$ and ${ }^{31} \mathrm{P}$ NMR, to confirm possible intermediates and products.

The reactions were followed by UV-Vis spectroscopy and the typical consecutive spectra obtained are shown in Figure 3a. It is possible to depict three important behaviors: (i) consumption of parathion at $270 \mathrm{~nm}$; (ii) formation of DEPT at $311 \mathrm{~nm}$ and (iii) formation of PNP at $400 \mathrm{~nm}$. In addition, an isosbestic point is observed at $290 \mathrm{~nm}$. The representative kinetic profiles obtained at each wavelength is given in Figure 3b, which all obey pseudo-first equations. Curiously, the results present a first indication that the reaction of imidazole with parathion is quite complicated, since it undergoes on both the phosphorus and aliphatic carbon electrophilic centers, due to the formation of their characteristic products: PNP and DEPT, respectively. It is interesting to note the small absorbance variation in the profiles of parathion and DEPT, which is significantly higher for PNP, that can be attributed to the greater molar absorptivity of PNP in contrast to parathion and DEPT. ${ }^{21}$

As mentioned, previously we showed that in the reaction of imidazole with the similar OPs methyl parathion, only one path was confirmed at the aliphatic carbon. ${ }^{21}$ Here, with parathion, we observe two concomitant reactions with imidazole. For comparison, Figure 4 shows the first

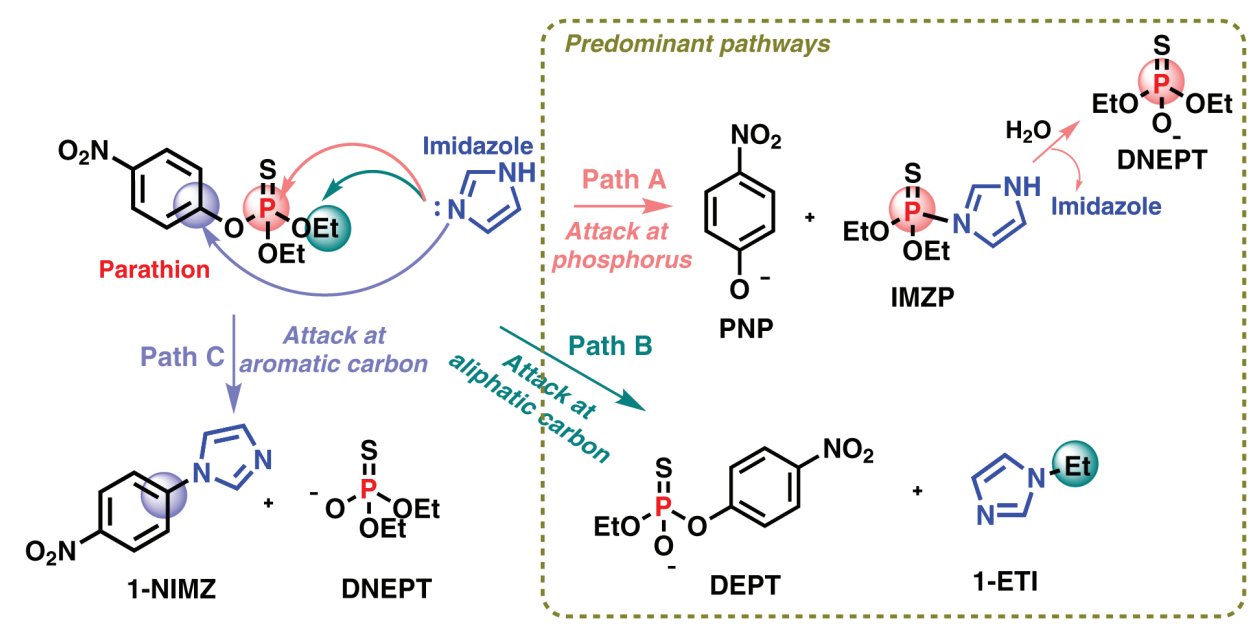

Figure 2. Possible pathways for the reaction of imidazole with parathion. 

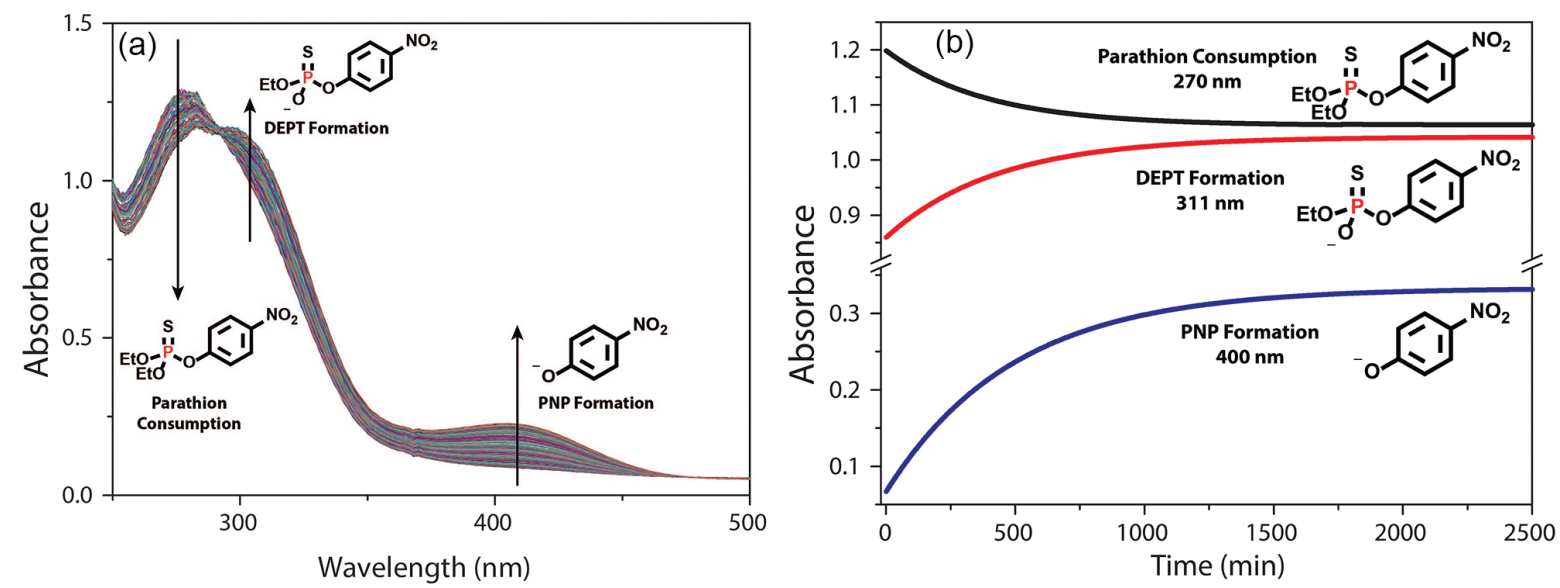

Figure 3. (a) Typical consecutive spectra obtained and (b) representative kinetic profiles obtained at various wavelengths, for the reaction of parathion $\left(6.8 \times 10^{-5} \mathrm{~mol} \mathrm{~L}^{-1}\right)$ and imidazole $\left(0.75 \mathrm{~mol} \mathrm{~L}^{-1}\right), 70{ }^{\circ} \mathrm{C}$.

and last spectra for the reactions of imidazole with methyl parathion and parathion. Clearly with methyl parathion, there is a negligible absorbance variation at $400 \mathrm{~nm}$, indicating that no significant amount of PNP is formed, hence attack at the phosphorus is not preferred. In fact, only an absorbance increase at $311 \mathrm{~nm}$ suggests the formation of the product due to the attack at the aliphatic carbon. This was solidly confirmed by various techniques such as NMR. ${ }^{21}$ For the reaction investigated herein, a distinct profile is observed. There is indeed a significant absorbance variation at both 270 and $400 \mathrm{~nm}$, consistent with two parallel reactions (paths A and B, Figure 2). Therefore, imidazole reacts differently, even with such similar OPs. Should this be accounted to the versatility of imidazole or can it be considered an undesired promiscuity? Surely this is a unique, unknown behavior of imidazole.

Another interesting kinetic analysis is evaluating the absorbance at $400 \mathrm{~nm}$ in order to speculate the degree of the reaction that proceeds at the phosphorus atom.

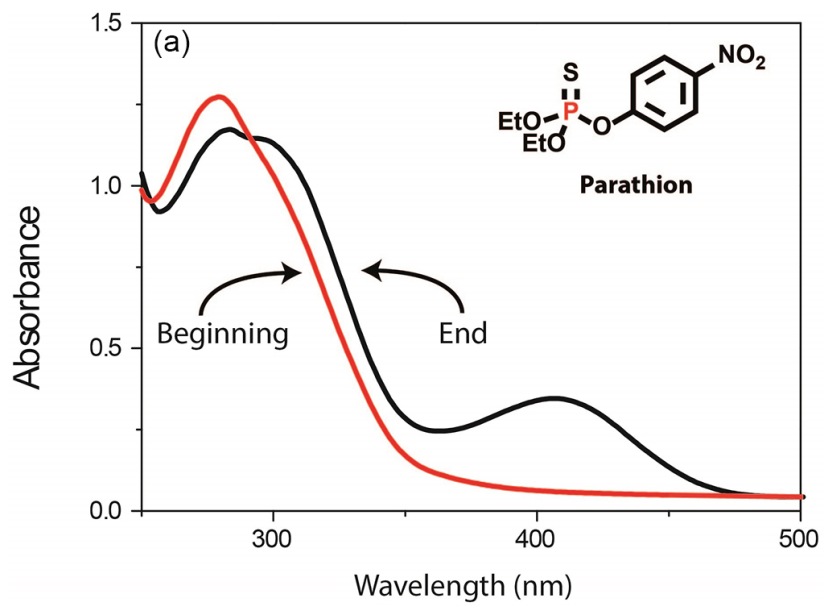

Figure 5a shows the spectra obtained at the end of the reaction for varying $\mathrm{pH}$. It is possible to see an expressive change in the profile at $400 \mathrm{~nm}$ with increasing $\mathrm{pH}$. This could not be attributed solely to the increase in the concentration of the anionic species of PNP which has a characteristic maximum absorbance at $400 \mathrm{~nm}$ (while neutral PNP at ca. $330 \mathrm{~nm}$ ), since given the estimated $\mathrm{p} K_{\mathrm{a}}$ of PNP of 6.67 at $70{ }^{\circ} \mathrm{C},{ }^{26}$ most of the spectra were obtained at $\mathrm{pH}$ above the $\mathrm{p} K_{\mathrm{a}}$. In fact, we estimated the conversion (\%) of parathion to the product PNP (path A, Figure 2) at different $\mathrm{pH}$, by comparing the observed final absorbance with the expected absorbance if all the reactant were to be converted to PNP. For that, we considered the molar absorptivity of the anionic species of PNP in $400 \mathrm{~nm}^{21}$ and considered the species distribution of the equilibrium involved. ${ }^{26}$ Figure $5 \mathrm{~b}$ shows the tendency of conversion, hence formation of PNP, as a function of $\mathrm{pH}$. It evidences that although a significant absorbance variation is observed at $400 \mathrm{~nm}$, barely $20 \%$ of the reaction occurs

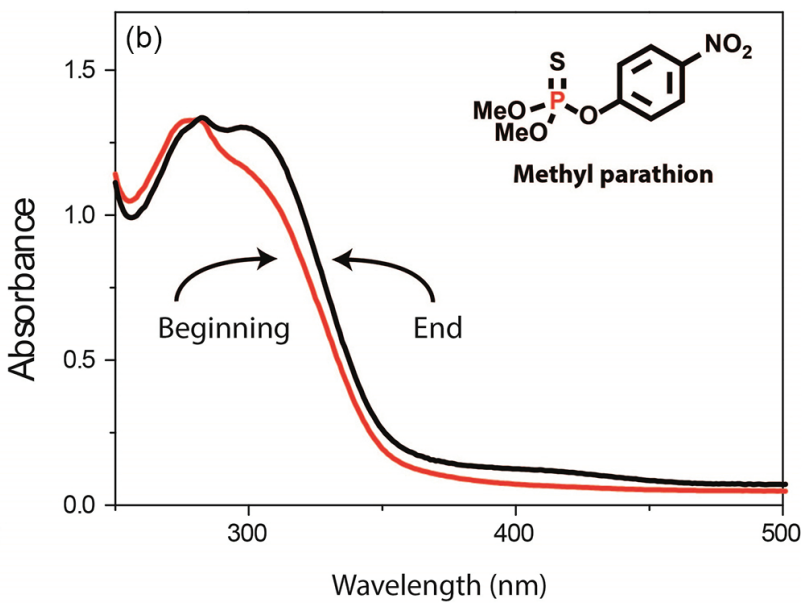

Figure 4. Typical spectra obtained at the beginning and at the end of the reactions of (a) imidazole with parathion $\left(0.75\right.$ and $6.8 \times 10^{-5} \mathrm{~mol} \mathrm{~L}^{-1}$, respectively, $\left.70^{\circ} \mathrm{C}\right)$ and (b) imidazole with methyl parathion $\left(1.00\right.$ and $5.0 \times 10^{-5} \mathrm{~mol} \mathrm{~L}^{-1}$, respectively, $\left.60^{\circ} \mathrm{C}\right)$. 

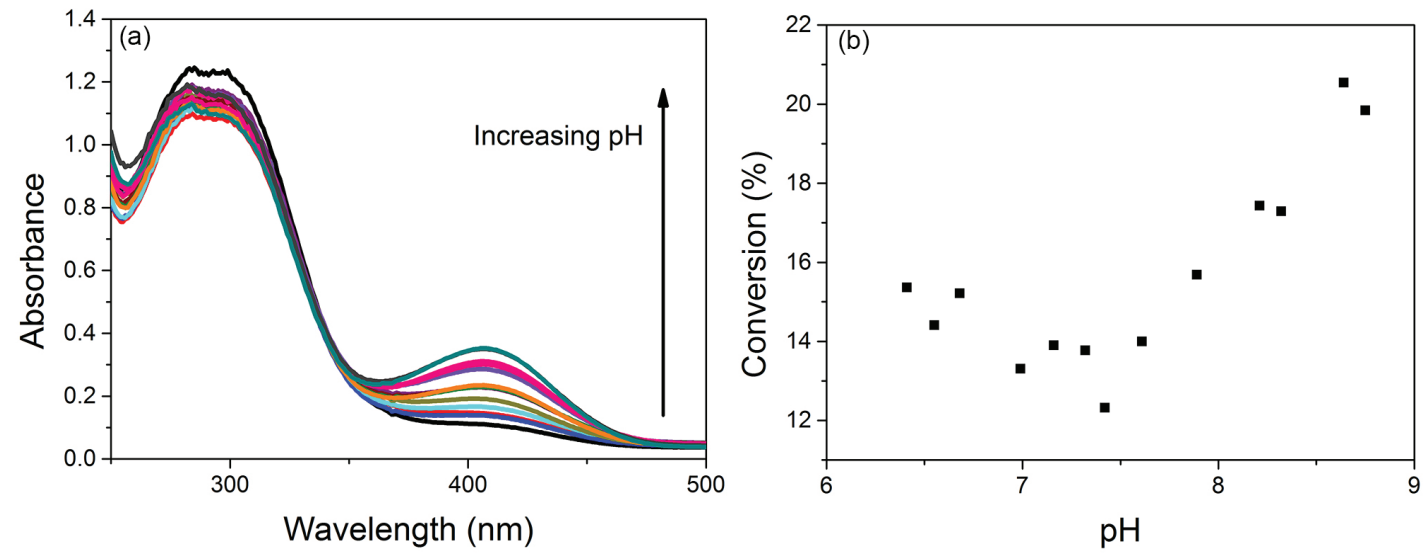

Figure 5. (a) Spectra obtained at the end of the reactions at each $\mathrm{pH}$ and (b) conversion of parathion to the product PNP, calculated at $400 \mathrm{~nm}$, considering the molar absorptivity of the anionic species, ${ }^{21,26}$ as a function of $\mathrm{pH}$, for the reaction of parathion $\left(6.8 \times 10^{-5} \mathrm{~mol} \mathrm{~L}^{-1}\right)$ and imidazole $\left(0.75 \mathrm{~mol} \mathrm{~L}^{-1}\right), 70{ }^{\circ} \mathrm{C}$.

at the phosphorus atom. Moreover, the preference for this path decreases at lower $\mathrm{pH}$, suggesting a favorable shift towards the aliphatic carbon. This observation suggests that the promiscuity of imidazole is even $\mathrm{pH}$-dependent. This behavior with parathion is not unprecedented since in another study, the reaction of parathion with hydroxide occurred preferably at the phosphorus at higher $\mathrm{pH}$, and at the aliphatic carbon at lower $\mathrm{pH} \cdot{ }^{27}$

Seeking a fuller understanding of the $\mathrm{pH}$ effect, a $\mathrm{pH}$ rate profile was obtained at $270 \mathrm{~nm}$, i.e., relative to the overall consumption of parathion, given in Figure 6. The analogous profiles at 311 and $400 \mathrm{~nm}$ could not be easily related to the one at $270 \mathrm{~nm}$. For example, the rate constant obtained at $270 \mathrm{~nm}$ could correspond to the sum of the rate constants obtained at 311 and $400 \mathrm{~nm}$, due to DEPT and PNP formation, respectively. This was not a straightforward analysis, attributed to the lack of isosbestic point between 311 and $400 \mathrm{~nm}$. Hence, the maximum absorbance increase at $400 \mathrm{~nm}$ also contributes to the variation at $311 \mathrm{~nm}$ and the absorbance contributions at 311 and $400 \mathrm{~nm}$ are overlapped. Nevertheless, it is clear that both products DEPT and PNP (paths A and B, Figure 2) are formed. In

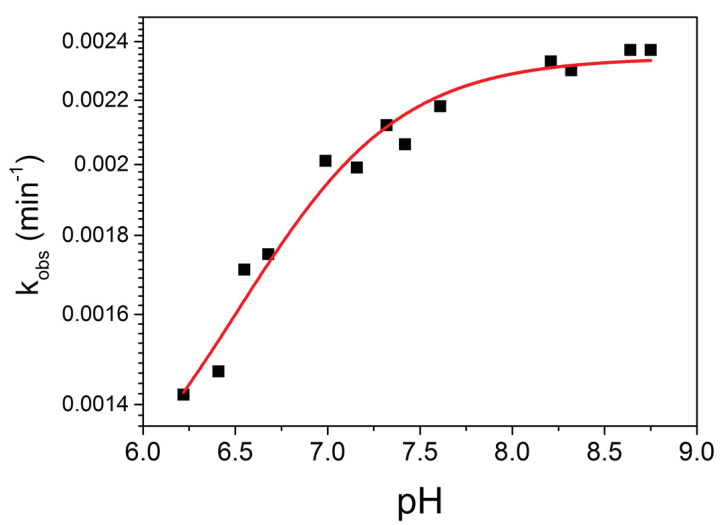

Figure 6. $\mathrm{pH}$ rate profile obtained at $270 \mathrm{~nm}$ for the reaction of parathion $\left(6.8 \times 10^{-5} \mathrm{~mol} \mathrm{~L}^{-1}\right)$ and imidazole $\left(0.75 \mathrm{~mol} \mathrm{~L}^{-1}\right), 70{ }^{\circ} \mathrm{C}$. the case at $270 \mathrm{~nm}$, the isosbestic point at $290 \mathrm{~nm}$ eliminates any other absorbance contribution, thus is reliable for analyzing the overall $\mathrm{pH}$ dependence in the present reaction by following this consumption of parathion. Analyses of Figure 6 shows a typical increase in the rate constant at higher $\mathrm{pH}$, until reaching a plateau. ${ }^{24}$ This indicates that the neutral species of imidazole is the most reactive, as depicted in Figure 2. The data in Figure 6 was fitted with the known equation for reactions with neutral imidazole. ${ }^{21}$ The kinetic $\mathrm{p} K_{\mathrm{a}}$ of 6.70 at $70{ }^{\circ} \mathrm{C}$ agrees with estimation from the literature ${ }^{28}\left(6.95\right.$ at $\left.25^{\circ} \mathrm{C}\right)$. The nucleophilic rate constant obtained from the fit is $1.60 \times 10^{-3} \mathrm{M}^{-1} \mathrm{~min}^{-1}$. This value is $7 \times 10^{3}$ fold higher than the hydrolytic rate constant (neutral $\mathrm{pH})$ reported in the literature $\left(2.31 \times 10^{-7} \mathrm{M}^{-1} \mathrm{~min}^{-1}\right.$ at $\left.70{ }^{\circ} \mathrm{C}\right) .{ }^{27}$ Comparison with other nucleophilic agents is difficult since other nucleophiles undergo reactions at the phosphorus (e.g., $\mathrm{OH}^{-}$), while here with imidazole there are two concomitant paths occurring. Nevertheless, the results confirm the efficiency of imidazole towards degrading parathion. Despite its apparent promiscuity, the high rate enhancements are impressive.

\section{NMR study}

Following the kinetic studies, ${ }^{1} \mathrm{H}$ and ${ }^{31} \mathrm{P}$ NMR analyses were used to investigate the reaction products. The reaction was carried out directly in the NMR tube under varying conditions: $\mathrm{pD} 7.2,8.2$ and 9.2. Due to the low solubility of parathion in water (around $38 \mu \mathrm{mol} \mathrm{L}^{-1}$ ), ${ }^{27}$ $40 \%$ of acetonitrile- $d_{3}$ was added to improve this, as done in similar studies. ${ }^{6,21}$ Figure 7 presents the typical consecutive ${ }^{31} \mathrm{P}$ NMR decoupled spectra obtained during the reactions for $\mathrm{pD} 7.2$ and 8.2, clearly evidencing the expected behavior of reagent disappearance and product formation. At pD 8.2 (Figure 7a) it is possible to depict 3 signals. At the beginning of the reaction, the signal 
at $62.7 \mathrm{ppm}$ was attributed to the reagent parathion, ${ }^{23}$ which decreases along the reaction. At the same time, two signals appeared, one at $52.3 \mathrm{ppm}$, attributed to DEPT. This product is not reported in the literature, but the chemical shift is similar to analogous methyl4-nitrophenyl thiophosphoric acid. ${ }^{21}$ In fact, the coupled ${ }^{31} \mathrm{P}$ spectrum of the final stages showed a triplet as expected for DEPT (shown in the SI section, Figure S31), confirming its structure. The coupling constant $J_{\mathrm{PH}} 8.6$ agrees to the double of quartet observed at $4.08 \mathrm{ppm}$ in the ${ }^{1} \mathrm{H}$ NMR spectra of the $-\mathrm{CH}_{2}$ aliphatic portion of DEPT (vide infra). The presence of DEPT solidly confirms the nucleophilic attack of imidazole at the aliphatic carbon of parathion (path B, Figure 2). Further, another signal of low intensity at $55.8 \mathrm{ppm}$ was found, which was attributed to DNEPT. ${ }^{29}$ We suggest this product was generated in a minor degree from the attack of imidazole at the phosphorus (path A, Figure 2). As predicted from previous kinetic results, this product is significantly less predominant. The phosphorylated intermediate IMZP was
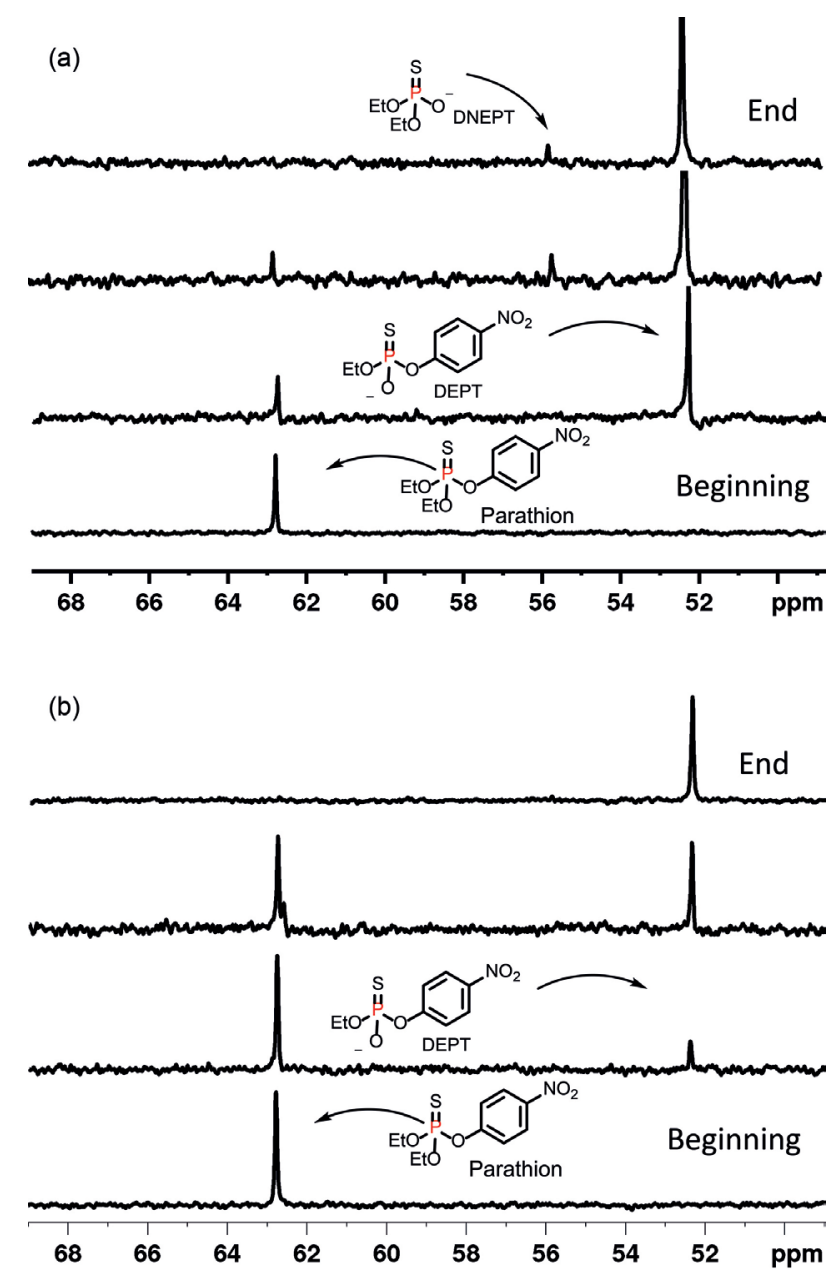

Figure 7. Sequential ${ }^{31} \mathrm{P}$ NMR spectra for the reaction at (a) $\mathrm{pD} 8.2$ and (b) $\mathrm{pD} 7.2$, of imidazole $\left(0.17 \mathrm{~mol} \mathrm{~L}^{-1}\right)$ with parathion $\left(8.50 \times 10^{-3} \mathrm{~mol} \mathrm{~L}^{-1}\right)$, $\mathrm{CD}_{3} \mathrm{CN} / \mathrm{D}_{2} \mathrm{O} 40: 60,80^{\circ} \mathrm{C}$. not observed probably due to its low concentration and its characteristic unstable nature. In the case of the reaction at lower pD, i.e., pD 7.2 (Figure 7b), only two signals were observed due to parathion and DEPT. The absence of a signal of DNEPT confirms that at lower pD, the attack of imidazole is almost exclusively at the aliphatic carbon and no significant amount of the product from the attack at the phosphorus (DNEPT) is detectable by this analysis. It is possible to see only the parathion signal (62.7) decreasing and the DEPT signal (52.3) increasing. Similar analysis is taken from the spectra of the reaction carried out $\mathrm{pD} 9.2$ (shown in the SI section, Figures S23-S29).

In the case of ${ }^{1} \mathrm{H} \mathrm{NMR}$, there are many overlapping signals and interferences from solvent mixture, although some relevant information can also be obtained. Figure 8 shows consecutive ${ }^{1} \mathrm{H}$ NMR spectra for the reaction of imidazole with parathion at $\mathrm{pD} 8.2$, while Table 1 presents an overall summary of all the signals depicted $\left({ }^{31} \mathrm{P}\right.$ and $\left.{ }^{1} \mathrm{H}\right)$. A set of new signals appears both at the aromatic and aliphatic region (for complete spectra, see SI section, Figures S3-S8), with the same multiplicity of parathion, only with small downshifts (Table 1). These signals are in

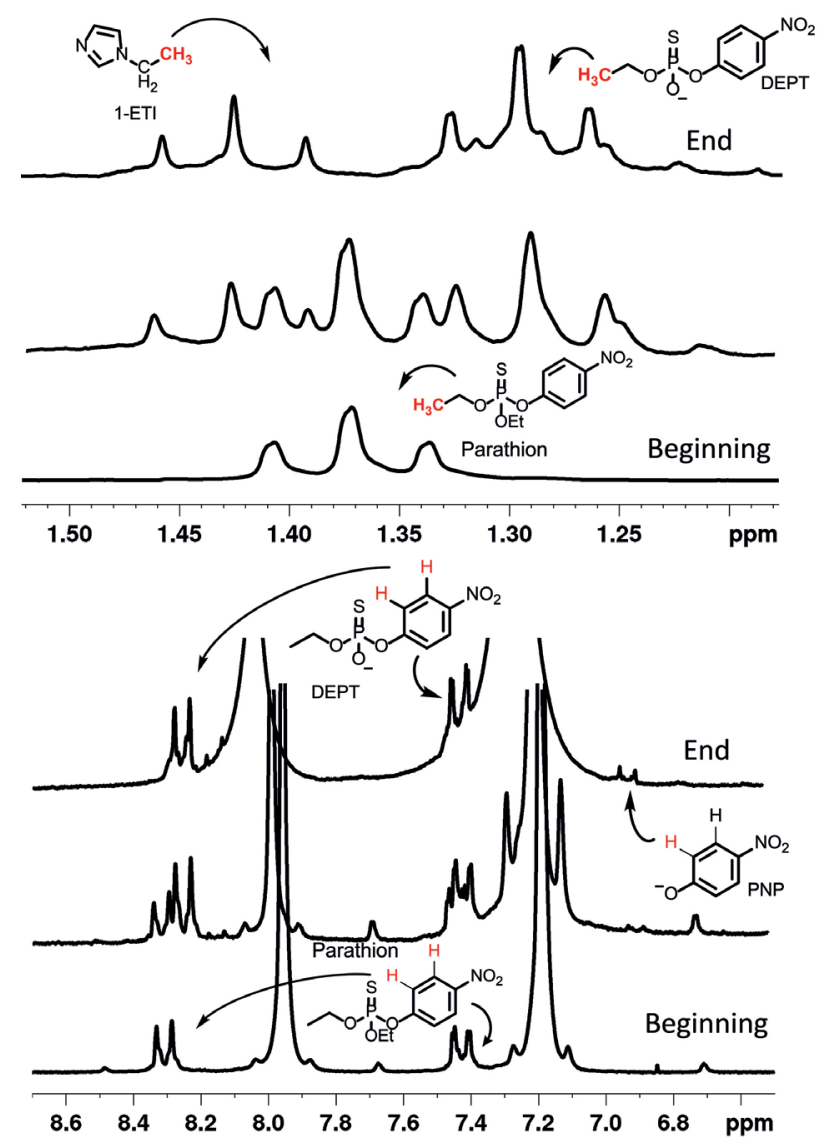

Figure 8. Sequential ${ }^{1} \mathrm{H}$ NMR spectra at the aliphatic and aromatic region for the reaction of imidazole $\left(0.17 \mathrm{~mol} \mathrm{~L}^{-1}\right)$ with parathion $\left(8.50 \times 10^{-3} \mathrm{~mol} \mathrm{~L}^{-1}\right), \mathrm{pD} 8.2, \mathrm{CD}_{3} \mathrm{CN} / \mathrm{D}_{2} \mathrm{O} 40: 60,80^{\circ} \mathrm{C}$. Complete spectra are given in the SI section. 
Table 1. Chemical shifts for the detected species in the reaction of imidazole with parathion ${ }^{\mathrm{a}}$

\begin{tabular}{|c|c|c|}
\hline & $\delta \mathrm{H} / \mathrm{ppm}$ & $\delta \mathrm{P} / \mathrm{ppm}$ \\
\hline Imidazole & $7.19(1 \mathrm{H})$ singlet and $7.96(2 \mathrm{H})$ singlet & - \\
\hline Parathion & $\begin{array}{c}1.37(6 \mathrm{H}) \text { triplet, } 4.30(4 \mathrm{H}) \text { double of } \\
\text { quartet, } 7.42(2 \mathrm{H}) \text { and } 8.30(2 \mathrm{H}) \mathrm{AA}^{\prime} \mathrm{XX} \\
\text { aromatic system }\end{array}$ & 62.8 \\
\hline DEPT & $\begin{array}{c}1.29(3 \mathrm{H}) \text { triplet, } 4.08(2 \mathrm{H}) \text { double of } \\
\text { quartet, } 7.41(2 \mathrm{H}) \text { and } 8.25(2 \mathrm{H}) \mathrm{AA}^{\prime} \mathrm{XX}^{\prime} \\
\text { aromatic system }\end{array}$ & 52.8 \\
\hline DNEPT & low intensity, overlapped & 55.7 \\
\hline 1-ETI & $\begin{array}{c}1.43(3 \mathrm{H}) \text { triplet, }-\mathrm{CH}_{2}-\text { overlapped by } \mathrm{H}_{2} \mathrm{O} \text {, } \\
\text { aromatic overlapped by imidazole }\end{array}$ & - \\
\hline PNP & $\begin{array}{c}6.87(2 \mathrm{H}) \text { and } 8.14(2 \mathrm{H}) \mathrm{AA}^{\prime} \mathrm{XX}^{\prime} \\
\text { aromatic system }\end{array}$ & - \\
\hline
\end{tabular}

a Selected here at pD 8.2, which can be slightly shifted in other $\mathrm{pD}$. DEPT: ethyl 4-nitrophenylthiophosphoric acid; DNEPT: diethyl thiophosphoric acid; 1-ETI: 1-ethyl imidazole; PNP: 4-nitrophenol.

agreement with the product DEPT from the attack at the aliphatic carbon (path B, Figure 2). In addition, it is possible to observe a triplet at $1.43 \mathrm{ppm}(\mathrm{J} 7.36 \mathrm{~Hz})$, assigned to the $-\mathrm{CH}_{3}$ aliphatic group of 1-ETI. This chemical shift and coupling constant agrees with the literature. ${ }^{30}$ The expected signals from $-\mathrm{CH}_{2}-$ and aromatic portion of 1-ETI are overlapped by the $\mathrm{H}_{2} \mathrm{O}$ and imidazole signals. Moreover, the hydrogen at the position 2 of imidazole in $\mathrm{D}_{2} \mathrm{O}$ undergoes a hydrogen-deuterium exchange reaction, eliminating its characteristic signal in the spectrum. ${ }^{31}$ These observations corroborate the nucleophilic attack of imidazole at the aliphatic carbon, analogously observed with methyl parathion. ${ }^{21}$ Further, the small contribution of the attack at the phosphorus is also confirmed in the aromatic region. Signals of low intensity around $7.0 \mathrm{ppm}$ are attributed to PNP. ${ }^{20}$ Due to the low concentration and overlapping with 1-EPT and DEPT, the signals from DNEPT cannot be clearly attributed in the ${ }^{1} \mathrm{H}$ NMR spectra. The absence of signals referent to 1-NIMZ are a strong indicative of no nucleophilic substitution at the aromatic center, discarding path $\mathrm{C}$ (Figure 2). ${ }^{32}$ Similar conclusions regarding the overall preferred mechanisms in the reaction evaluated were obtained from the spectra taken from the reaction at other $\mathrm{pD}$ conditions (shown in the SI section, Figures S3-S8 and S23-S26). Although, upon varying pD, the signals of imidazole at the aromatic region suffer an upshift due to protonation overlapping the signals from parathion and DEPT.

In summary, NMR analyses consistently confirmed the puzzling mechanistic outcome of imidazole towards parathion: a dual nucleophilic attack at the phosphorus and aliphatic carbon. The major product detected was
DEPT, while PNP and DNEPT showed significantly lower intensity, confirming that the attack at the aliphatic carbon is predominant (path B, Figure 2). In addition, the $\mathrm{pH}$-modulation of the mechanism is also supported by NMR, since at lower pD, the attack at the phosphorus (path A, Figure 2) is disfavored.

\section{Imidazoles: versatile or promiscuous?}

Imidazole is notably very catalytic towards several OPs and shows broad spectra of mechanistic pathways. This versatility has benefited many enzymatic active sites and bioinspired many mimetic catalysts. A concise understanding of the mechanism underlying OPs is imperative for effectively applying in real destruction or monitoring systems. The most efficient destruction process will be that which leads to less toxic products, and preferably with no side reactions. In addition, one monitoring system may not apply to various toxic OPs, since their structure can shift the mechanism, hence lead to different products and suppress important signals or give false positives. Many studies show that the presence of imidazole on various scaffolds has shown to increase the reaction efficiency, mostly leading to faster reactions. Figure 9 summarizes several reactions involving OPs and the imidazole group, illustrating its mechanistic versatility towards the $\mathrm{P}=\mathrm{O}$ and $\mathrm{P}=\mathrm{S}$ family. An interesting case is the hydrolysis of the monoester 2-(2'-imidazolium) phenyl hydrogen phosphate (IMPP) ${ }^{33}$ which profits from an intramolecular general acid catalysis by the imidazolium moiety with an efficiency of $10^{9}$-fold rate enhancement, compared to analogous reaction in the absence of imidazole. Similarly, neutral imidazole can act as a general basic catalyst assisting in the intramolecular cyclisation of methyl phenyl 1,2-isopropyl idene-P- $\beta$-xylofuranose 3 '-phosphate triester (MPT) ${ }^{34}$ One of the most prevailing mechanisms shown by neutral imidazole is nucleophilic. For example, a series of aryl phosphoimidazoles such as $o$-(2'-imidazolyl)naphthyl (4-nitrophenyl) phosphate $(3 \mathrm{NIP})^{35}$ evidence an intramolecular nucleophilic catalysis by the neighboring imidazole, confirmed by the detection of the cyclic intermediate. Moreover, for the series of esters derived from 2,4-dinitrophenol: diester bis(2,4-dinitrophenyl) phosphate (BDNPP), diester ethyl2,4-dinitrophenyl phosphate (EDNPP) and the triester diethyl-2,4-dinitrophenyl phosphate (DEDNPP), imidazole also reacts as a nucleophilic catalyst with rate enhancements over $10^{3}$-fold, compared to the spontaneous reactions. In this case, various phosphorylimidazole intermediates were detected and their lifetimes were determined. ${ }^{19}$ For esters derived from 4-nitrophenol (PNP), such as the 


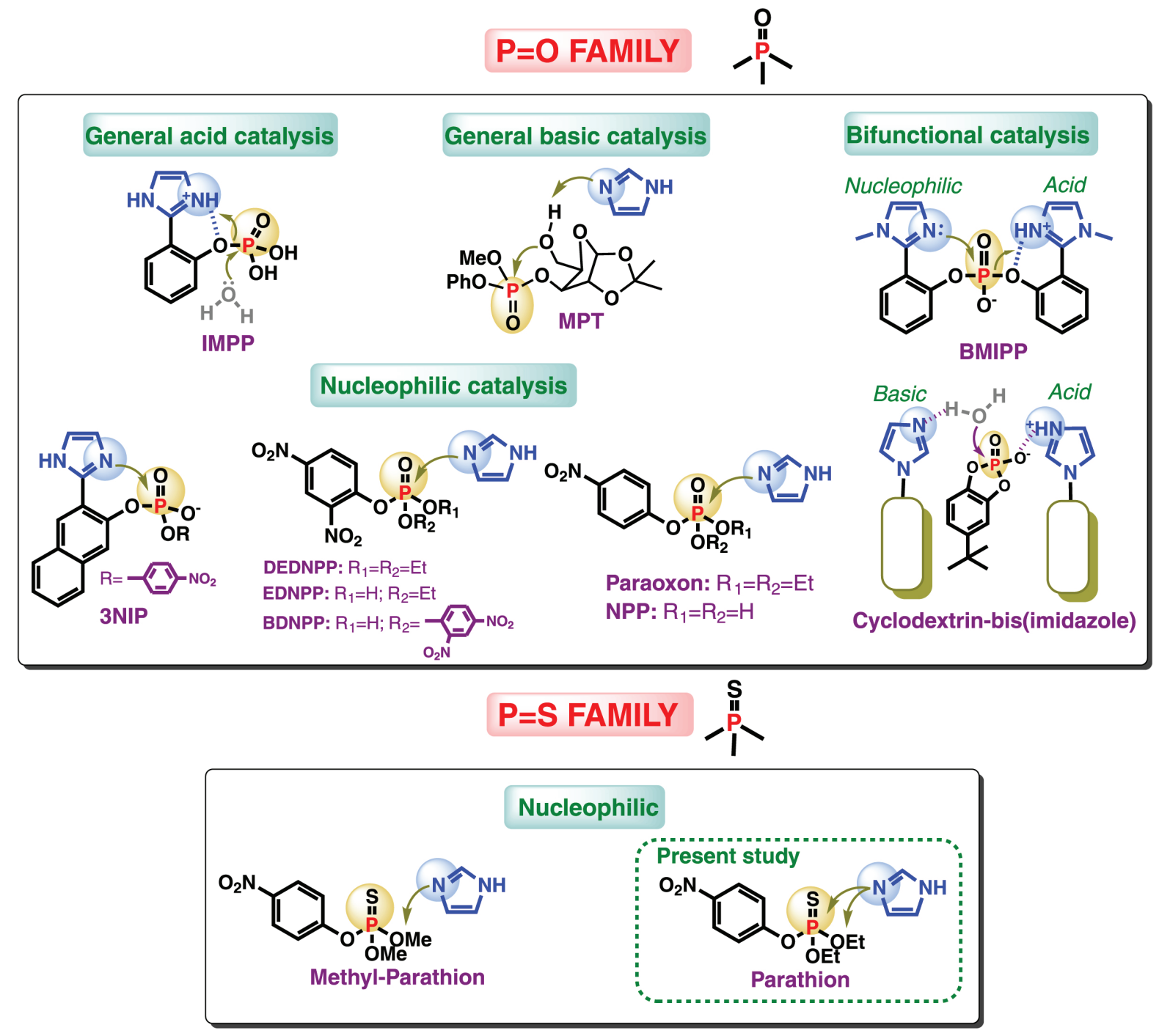

Figure 9. Various reported reactions of imidazole with $\mathrm{OPs}$, showing its versatility towards the $\mathrm{P}=\mathrm{O}$ and $\mathrm{P}=\mathrm{S}$ family, ${ }^{19-21,33-38}$ including the present study.

monoester 4-nitrophenylphosphate (NPP) ${ }^{36}$ or the triester paraoxon, ${ }^{20}$ an analogous mechanism was unraveled. Imidazole reacts with paraoxon with impressive rate enhancements of $10^{6}$-fold, among the highest reported. The wide versatility of imidazole has even enabled the development of bifunctional catalysts. The typical bell-shaped $\mathrm{pH}$ rate profile observed for the hydrolysis of the diester bis(2-(1-methyl-1H-imidazolyl)phenyl) phosphate (BMIPP) $)^{37}$ is characteristic of an intramolecular bifunctional catalysis: while one neutral imidazole acts as a nucleophile, another neighboring protonated imidazolium assists as a general acid catalyst. This efficiency reaches up to $10^{11}$-fold rate enhancements. In another study, cyclodextrin-bis(imidazole) reacts with a phosphodiester via a concomitant bifunctional general acid-basic catalysis. ${ }^{38}$ All the examples above relate to the $\mathrm{P}=\mathrm{O}$ family. More recently, the $\mathrm{P}=\mathrm{S}$ family has attracted great interest due to the apparent thio effect in shifting the mechanism and also to the presence of $\mathrm{P}=\mathrm{S}$ in many agrochemicals and chemical warfare. They are available in supermarkets in anti-flea collars for cats, for example. Unfortunately, there are only a few studies reported with imidazole with OPs from the $\mathrm{P}=\mathrm{S}$ family. Previously, we showed that methyl parathion reacts with imidazole exclusively at the aliphatic carbon. ${ }^{21}$ This finding was puzzling since with the analogous $\mathrm{OP}$ containing $\mathrm{P}=\mathrm{O}$ (paraoxon), the reactions with imidazole occur only at the phosphorus. ${ }^{21}$ Hence, another side of the versatility of imidazole arises. Not only it can vary its mode of action (general acid-basic, nucleophilic) but also it can react at different electrophilic centers in analogous structures. Further, we show here that with parathion, greatly similar to methyl parathion, imidazole reacts by two pathways that can be modulated by the $\mathrm{pH}$. Nonetheless, the predominant reaction is also the unusual attack at the aliphatic carbon, giving ethylated imidazole. How to understand and predict this trend? Does 
this deviate from a noble versatility and represents barely promiscuity? Is the driving force attributed to the versatility of imidazole or to the complexity of the "thio effect" in OPs? Surely there is no definitive answer to these questions and many future efforts are necessary in order to address these issues. Although, we believe studies such as the one presented here are fundamental for decoding the puzzle and comprehensively understanding how these reactions occur. Unquestionably, imidazole can greatly diversify its mechanistic action, not only on how the nitrogen atom catalyzes but also towards with which electrophilic centers it reacts. $N$-Phosphorylation is widely known for imidazole and the most striking finding that $N$-alkylation also occurs in the same reaction opens a myriad of possibilities. We consider this beneficial, which adds to the versatile nature of imidazole.

Regarding elucidating the structure-related trends, imidazole seems to prefer nucleophilic attack at the phosphorus atom for more reactive OPs, such as those derived from dinitrophenol (DEDNPP, EDNPP and BDNPP, Figure 9), which greatly increases the electrophilicity of the phosphoryl. Even for less reactive OPs derived from nitrophenol, such as paraoxon and NPP (Figure 9), imidazole attacks the phosphorus. Albeit, in the case of methyl parathion (Figure 9), the phosphorus of the $\mathrm{P}=\mathrm{S}$ family is knowingly less electrophilic than the respective $\mathrm{P}=\mathrm{O}$ family. ${ }^{6}$ Hence, for considerably lower reactivity, imidazole prefers to the attack the aliphatic carbon. In another study, bisulfide $\left(\mathrm{HS}^{-}\right)$also reacts towards the aliphatic carbon for a series of thio OPs. ${ }^{39}$ It should be noted that in studies with OPs derived from dinitrophenol from the $\mathrm{P}=\mathrm{O}$ and $\mathrm{P}=\mathrm{S}$ family, authors show that for the $\mathrm{P}=\mathrm{S}$ family, several amines prefer to attack the aromatic carbon, rather to the phosphorus. ${ }^{6}$ This is consistent with our observation, i.e., the attack at the aromatic carbon is unfavorable herein with imidazole. Thus, it seeks another target instead of the phosphorus and prefers to react with the aliphatic carbon. In the case of parathion, the ethyl group usually decreases the reactivity ${ }^{40}$ due to the inductive effect, but imidazole does not prefer exclusively the aliphatic carbon in this case. This could be attributed to two effects: (i) possible steric hindrance by the ethyl, hampering the attack; (ii) decreased electrophilic character of the aliphatic carbon of ethylene carbon due to the inductive effect of the neighboring methyl group. Anyway, the results show roughly more than $80 \%$ favorable attack at the aliphatic carbon. Thusly, the behavior of imidazole towards OPs seems to follow a trend: with less reactive OPs, imidazole tends to prefer other electrophilic centers other than the phosphorus. This gives important insights concerning the challenging chemistry of imidazole ${ }^{41}$ and its feasible alkylation. The synthesis of 1-methylimidazole and 1-ethylimidazole can be accomplished in an aqueous weakly basic medium, a breakthrough for organic synthesis. Specially, when considering that this is undertaken from the destruction process of OPs. Hence, unwanted stockpiles can be efficiently degraded and in addition be used as a source for synthesizing alkylimidazoles.

Another intriguing finding is that the $\mathrm{pH}$ also affects the reaction course for the reaction of parathion with imidazole. Rough estimations from kinetic studies indicate that the attack at the phosphorus goes from nearly $20 \%$ at higher $\mathrm{pH}$ (ca. 9) and decreases up to $14 \%$ at lower $\mathrm{pH}$ (ca. 7), which was confirmed by NMR analysis. This agrees with previous reports that evidence a predominance of the attack at the phosphorus for the hydrolysis of parathion at higher $\mathrm{pH}(>10)$, while at lower $\mathrm{pH}$ (ca. 7), the reactions occur exclusively at the aliphatic carbon. ${ }^{27}$ In fact, this $\mathrm{pH}$ dependence is also an important ally when targeting specific reactions pathways.

\section{Conclusions}

Following up on the initial inquiry, the promiscuity of imidazole boosts up its versatility, certainly. While in some cases imidazole reacts exclusively at one electrophilic center, herein with parathion it can react concomitantly with both targets, but with significantly greater prevalence for one center (aliphatic carbon) that can be further modulated by the $\mathrm{pH}$ (ca. $10 \%$ at the phosphorus atom at $\mathrm{pH} 7$ ). Two products are usually unwanted, but this enlightens the mechanistic trends with imidazole. Possibly with other OPs, only one product can be formed and a full understanding of the promiscuity of imidazole will guide towards taking advantage of its versatility. Likewise, future studies with a broader $\mathrm{P}=\mathrm{S}$ family is necessary and surely manipulating the reactivity of imidazole (e.g., varying substituents) should incite novel discoveries.

\section{Supplementary Information}

Supplementary information (kinetic equations and additional NMR spectra) is available free of charge at http://jbcs.sbq.org.br as a PDF file.

\section{Acknowledgments}

Authors acknowledge the financial support from UFPR, CNPq, CAPES, L'Oréal-UNESCO-ABC, PhosAgro/UNESCO/IUPAC, Fundação Araucária and National Institute of Science and Technology of Carbon Nanomaterials (INCT-Nanocarbon). This study was 
financed in part by the Coordenação de Aperfeiçoamento de Pessoal de Nível Superior (CAPES), Brasil, finance code 001 .

\section{References}

1. Costa, L. G.; Toxicol. Sci. 2017, 162, 24.

2. Hertz-Picciotto, I.; Sass, J. B.; Engel, S.; Bennett, D. H.; Bradman, A.; Eskenazi, B.; Lanphear, B.; Whyatt, R.; PLoS Med. 2018, 15, e1002671.

3. Pirsaheb, M.; Hossini, H.; Asadi, F.; Janjani, H.; Toxin Rev. 2017, 36, 210.

4. Costanzi, S.; Machado, J.-H.; Mitchell, M.; ACS Chem. Neurosci. 2018, 9, 873.

5. Groenewold, G. S.; Main Group Chem. 2010, 9, 221.

6. Aguayo, R.; Arias, F.; Cañete, A.; Zuñiga, C.; Castro, E. A.; Pavez, P.; Santos, J. G.; Int. J. Chem. Kinet. 2013, 45, 202.

7. Vickery, H. B.; Leavenworth, C. S.; J. Biol. Chem. 1928, 78, 627.

8. King, H.; Obit. Not. Fellows R. Soc. 1944, 4, 681.

9. Bruice, T. C.; Schmir, G. L.; J. Am. Chem. Soc. 1957, 79, 1663.

10. Bender, M. L.; Turnquest, B. W.; J. Am. Chem. Soc. 1957, 79, 1656.

11. Jencks, W. P.; Carriuolo, J.; J. Biol. Chem. 1959, 234, 1280.

12. Sowa, G. A.; Hengge, A. C.; Cleland, W.; J. Am. Chem. Soc. 1997, 119, 2319.

13. Herschlag, D.; J. Am. Chem. Soc. 1994, 116, 11631.

14. Breslow, R.; Dong, S. D.; Webb, Y.; Xu, R.; J. Am. Chem. Soc. 1996, 118, 6588.

15. Ba-Saif, S. A.; Williams, A.; J. Org. Chem. 1988, 53, 2204.

16. Purcell, J.; Hengge, A. C.; J. Org. Chem. 2005, 70, 8437.

17. Carvalho, A. T.; O’ Donoghue, A. C.; Hodgson, D. R.; Kamerlin, S. C.; Org. Biomol. Chem. 2015, 13, 5391.

18. Rougier, N. M.; Vico, R. V.; de Rossi, R. H.; Buján, E. I.; J. Org. Chem. 2010, 75, 3427.

19. Orth, E. S.; Wanderlind, E. H.; Medeiros, M.; Oliveira, P. S.; Vaz, B. G.; Eberlin, M. N.; Kirby, A. J.; Nome, F.; J. Org. Chem. 2011, 76, 8003.

20. Orth, E. S.; Almeida, T. G.; Silva, V. B.; Oliveira, A. R. M.; Ocampos, F. M. M.; Barison, A.; J. Mol. Catal. A: Chem. 2015, 403, 93.
21. Silva, V. B.; Nascimento, L.; Nunes, M.; Campos, R.; Oliveira, A.; Orth, E. S.; Chem. - Eur. J. 2019, 25, 817.

22. Timperley, C. M.; Best Synthetic Methods: Organophosphorus(V) Chemistry; Academic Press: Amsterdan, 2014.

23. Tamilselvi, A.; Mugesh, G.; Chem. - Eur. J. 2010, 16, 8878.

24. Campos, R. B.; Menezes, L. R.; Barison, A.; Tantillo, D. J.; Orth, E. S.; Chem. - Eur. J. 2016, 22, 15521.

25. Wanderlind, E. H.; Medeiros, M.; Souza, B. S.; Fiedler, H. D.; Nome, F.; Rev. Virtual Quim. 2014, 6, 632.

26. Ehlerova, J.; Trevani, L.; Sedlbauer, J.; Tremaine, P.; J. Solution Chem. 2008, 37, 857.

27. Wanamaker, E. C.; Chingas, G. C.; McDougal, O. M.; Environ. Sci. Technol. 2013, 47, 9267.

28. Goldberg, R. N.; Kishore, N.; Lennen, R. M.; J. Phys. Chem. Ref. Data 2002, 31, 231.

29. Santos, J.; Aliaga, M.; Alarcón, K.; Torres, A.; Céspedes, D.; Pavez, P.; Org. Biomol. Chem. 2016, 14, 6479.

30. Kumar, N.; Jain, R.; J. Heterocycl. Chem. 2012, 49, 370.

31. Vaughan, J. D.; Mughrabi, Z.; Wu, E. C.; J. Org. Chem. 1970, 35,1141 .

32. Liu, X.; Chang, S.; Chen, X.; Ge, X.; Qian, C.; New J. Chem. 2018, 42, 16013.

33. Brandão, T. A. S.; Orth, E. S.; Rocha, W. R.; Bortoluzzi, A. J.; Bunton, C. A.; Nome, F.; J. Org. Chem. 2007, 72, 3800.

34. Chandler, A. J.; Hollfelder, F.; Kirby, A. J.; O'Carroll, F.; Strömberg, R.; J. Chem. Soc., Perkin Trans. 2 1994, 327.

35. Pereira, M. S.; Murta, B.; Oliveira, T. C.; Manfredi, A. M.; Nome, F.; Hengge, A. C.; Brandão, T. A.; J. Org. Chem. 2016, 81,8663

36. Kirby, A.; Jencks, W.; J. Am. Chem. Soc. 1965, 87, 3209.

37. Orth, E. S.; Brandao, T. A. S.; Souza, B. S.; Pliego, J. R.; Vaz, B. G.; Eberlin, M. N.; Kirby, A. J.; Nome, F.; J. Am. Chem. Soc. 2010, 132, 8513.

38. Breslow, R.; Acc. Chem. Res. 1995, 28, 146.

39. Wu, T.; Gan, Q.; Jans, U.; Environ. Sci. Technol. 2006, 40, 5428.

40. Faust, S. D.; Gomaa, H. M.; Environ. Lett. 1972, 3, 171.

41. Rossa, T. A.; Fantinel, M.; Bortoluzzi, A. J.; Sá, M. M.; Eur. J. Org. Chem. 2018, 2018, 4171.

Submitted: February 6, 2019

Published online: May 8, 2019 